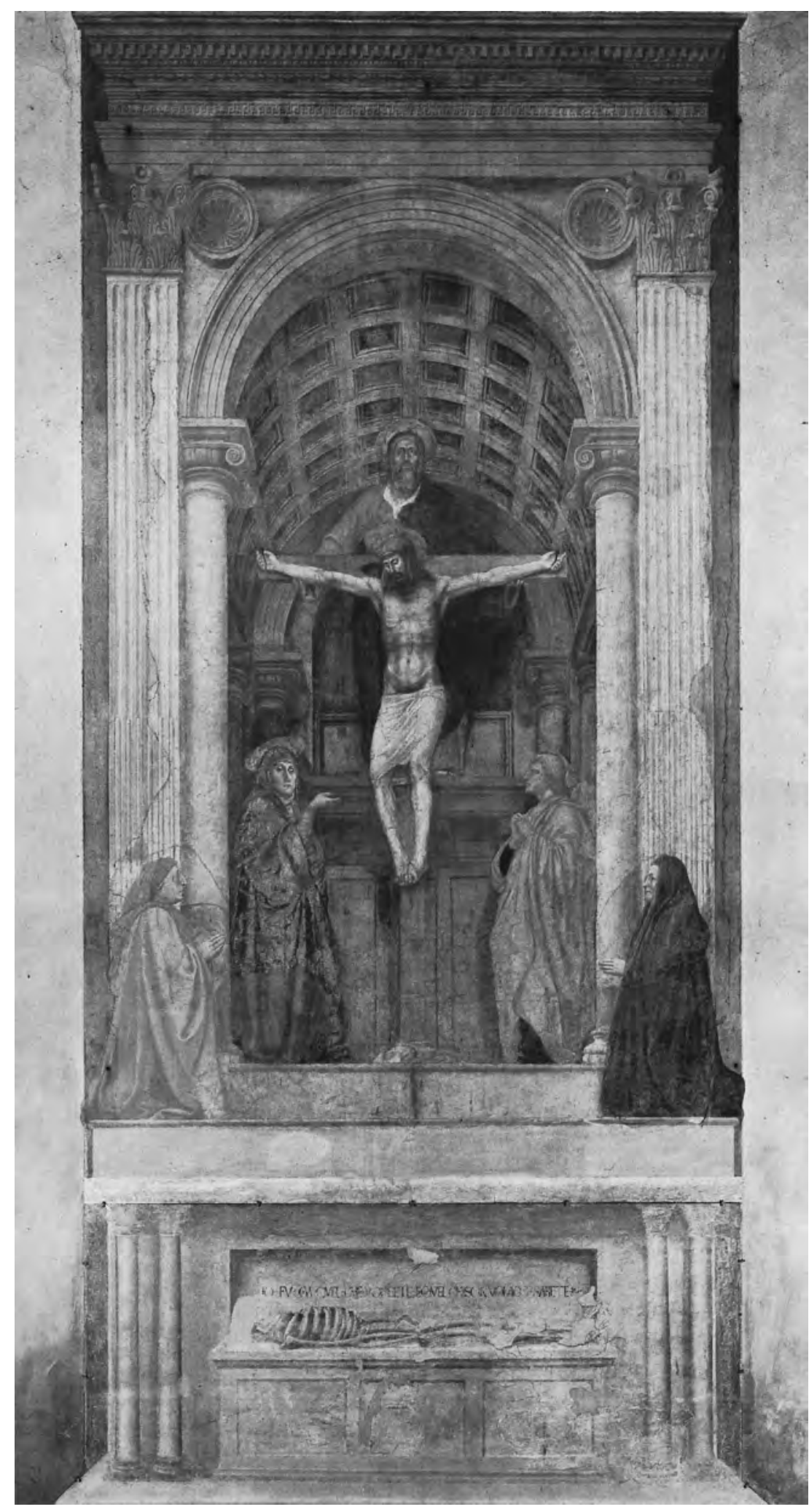

Figura 1: Masaccio, fresco de la Trinidad. Fuente: Colección Los genios de la pintura, Madrid: Sarpe, 1979, tomo 50, lám. 21.

\section{El juego de los tuertos Miradas críticas sobre la perspectiva renacentista y la ciencia moderna}

Prof. María Inés Prono, Docente investigadora FHUC-FADU/UNL

Arq. Matías Aimino, Docente Fadu/unl

La perspectiva renacentista ha sido un ejemplo insistentemente trabajado en la literatura epistemológica, dado que permite establecer relaciones con la constitución de la ciencia moderna y, a la vez, ofrece una fecunda metáfora respecto de la actividad cognoscente propia de este modelo de racionalidad. En este trabajo, pretendemos examinar el uso crítico de esta metáfora y, para ello, seleccionamos tres lecturas procedentes de diferentes orígenes y orientaciones teóricas que, a nuestro juicio, coinciden en:

- la preocupación por mostrar que la asociación de estos modos de representación con el realismo está lejos de ser obvia y directa; $y$

- una cierta conciencia de haber pagado un costo muy alto por la sistematización y racionalización a las que han conducido estos modos de representación.

En lo que sigue, nuestra intención será analizar y cotejar estas lecturas, considerando los modos en que reconstruyen la cuestión del realismo de las representaciones y destacando las diversas vías que ofrecen para transformar nuestra comprensión de la actividad cognoscente. Por último, puntualizaremos algunos rasgos de una concepción revisada de la ciencia, a la luz del debate contemporáneo.

\section{La perspectiva:}

\section{historia y cambios en los hábitos perceptivos}

P. Thuillier (1988) sostiene, entre otros, que la invención de la perspectiva durante el Renacimiento constituye un antecedente determinante en el cambio de hábitos perceptivos que posibilitan el surgimiento de la concepción del espacio de la ciencia moderna. Los artistas florenti- 
nos serían los protagonistas de una revolución silenciosa que prepara el camino para la sistematización de la noción de espacio llevada a cabo por los científicos del siglo XVII. Ambos modos de representación comparten el recurso a la matematización o geometrización del espacio, con el que se pretende alcanzar una representación verídica de la realidad. Por esto, suele afirmarse que la perspectiva renacentista y la ciencia moderna presentan rasgos de realismo y racionalismo que constituirían, presuntamente, sus atributos primordiales.

Como historiador de la ciencia, Thuillier se alinea entre aquéllos que pretenden dejar de lado el purismo intelectual y que intentan mostrar que el surgimiento de la perspectiva, y de su concomitante noción de espacio, ha sido producto de una larga cadena de modificaciones socioculturales, profundamente arraigadas en prácticas no científicas. Su aparición, en todo caso, habría estado sobredeterminada, y más que como una revolución puede verse como una evolución, en algún sentido, inevitable.

En la Italia del los siglos XIV y XV, el desarrollo de las matemáticas prácticas comienza a extenderse a muchas formas de la vida social. La llegada del empresariado contribuye a que el arte de medir y calcular tenga cada vez más importancia, hasta llegar a constituirse como un hábito cultural presente en diversas actividades: en los talleres de mecánica y en los arsenales, en el trabajo de los artilleros, en el cálculo de volúmenes y beneficios del comercio, en la disposición de los terrenos cultivables, en el trazado de fronteras. La eficacia, el orden y la organización racional de las actividades comienzan a verse como beneficios posibilitados por la matematización.

En cuanto a los artistas, Brunelleschi realiza hacia 1425 varios experimentos ópticos, y Masaccio pinta el fresco de la Trinidad, considerado como la primera aplicación rigurosa del punto de fuga (Figura 1). Pero fue León Battista Alberti, quien en 1435, en su tratado De la pintura, formula la primera elaboración teórica de la perspectiva. Apoyado en conocimientos de óptica y geometría, sostiene que la representación del espacio debe estudiarse analizando los triángulos y demás figuras formadas por los rayos visuales. Los críticos coinciden en que la exposición de Alberti adolece, en muchos aspectos, de lagunas significativas, pero es claro que la mirada que los pintores dirigen a las cosas se modifica, de algún modo, se geometriza y permite apreciar un nuevo sentido del espacio. Por esto, sostiene Thuillier, «no resulta exagerado decir que la perspectiva, más que una ciencia especulativa, era la expresión de una filosofía práctica, de una especie de proyecto para reorganizar a la vez el espacio real y la representación de dicho espacio» (Thuiller 1988:151).
Siguiendo este camino, las transformaciones en la mirada de los artistas constituyen la preparación para las teorizaciones de la ciencia, y como se ha sugerido, la práctica precede a la teoría. Esto significa que la representación racional del espacio sólo alcanzará una elaboración conceptual adecuada, y una precisión suficiente, con las investigaciones de Galileo y Descartes.

Una cierta forma de realismo y racionalismo van abriéndose paso: el conocimiento de las leyes geométricas que regulan y organizan el espacio hace manifiesto un mundo que se concibe como independiente, puesto que reposa sobre una estructura objetiva que no nos pertenece. Estos dos rasgos llegan a ser considerados como criterios universales a partir de los cuales se puede juzgar la legitimidad de las producciones científicas y artísticas; se convierten entonces en la medida o patrón de toda representación verídica.

Sin embargo, la representación en perspectiva parte de dos presuposiciones, fundamentales pero inverificables, acerca de la percepción: (a) que miramos con un solo ojo inmóvil y (b) que la intersección plana de la pirámide visual debe considerarse como una reproducción adecuada de lo que percibimos. La presencia de estos dos supuestos hace necesario tomar ciertos recaudos en cuanto al valor objetivo de la perspectiva clásica. En principio, no puede afirmarse que tenga valor absoluto, sino que es un sistema de representación entre otros, ofrece comodidad y sencillez, y por sobre todo crea la ilusión de una representación fiel de la realidad.

Según Thuillier, «que este sistema tenga su racionalidad propia y permita poner orden en la percepción, resulta poco dudoso. Pero sin duda conviene no identificar pura y simplemente esta reconstrucción con el espacio real; se trata precisamente de una reconstrucción basada en presupuestos que, en el mejor de los casos, conducen a una simplificación de nuestros procesos perceptivos» (Thuillier 1988:159). Cabe destacar, sin embargo, que esta voluntad de simplificación y abstracción no es exclusiva de la representación perspectívica, sino que ha alcanzado a gran parte de los desarrollos de la modernidad y, particularmente, a la ciencia.

\section{El rol de la perspectiva}

en la construcción del realismo y la objetividad científica

E. Fox Keller (1994) aborda la lógica de la representación científica a través del análisis de ciertos hitos que le permiten indagar el proceso histórico por el cual la subjetividad ha sido sistemáticamente elidida de la producción científica o, al menos, del modo en que la ciencia misma presenta esa producción. El primero de los hitos considerados es la perspectiva clásica en tanto metáfora del conocimiento científico. 


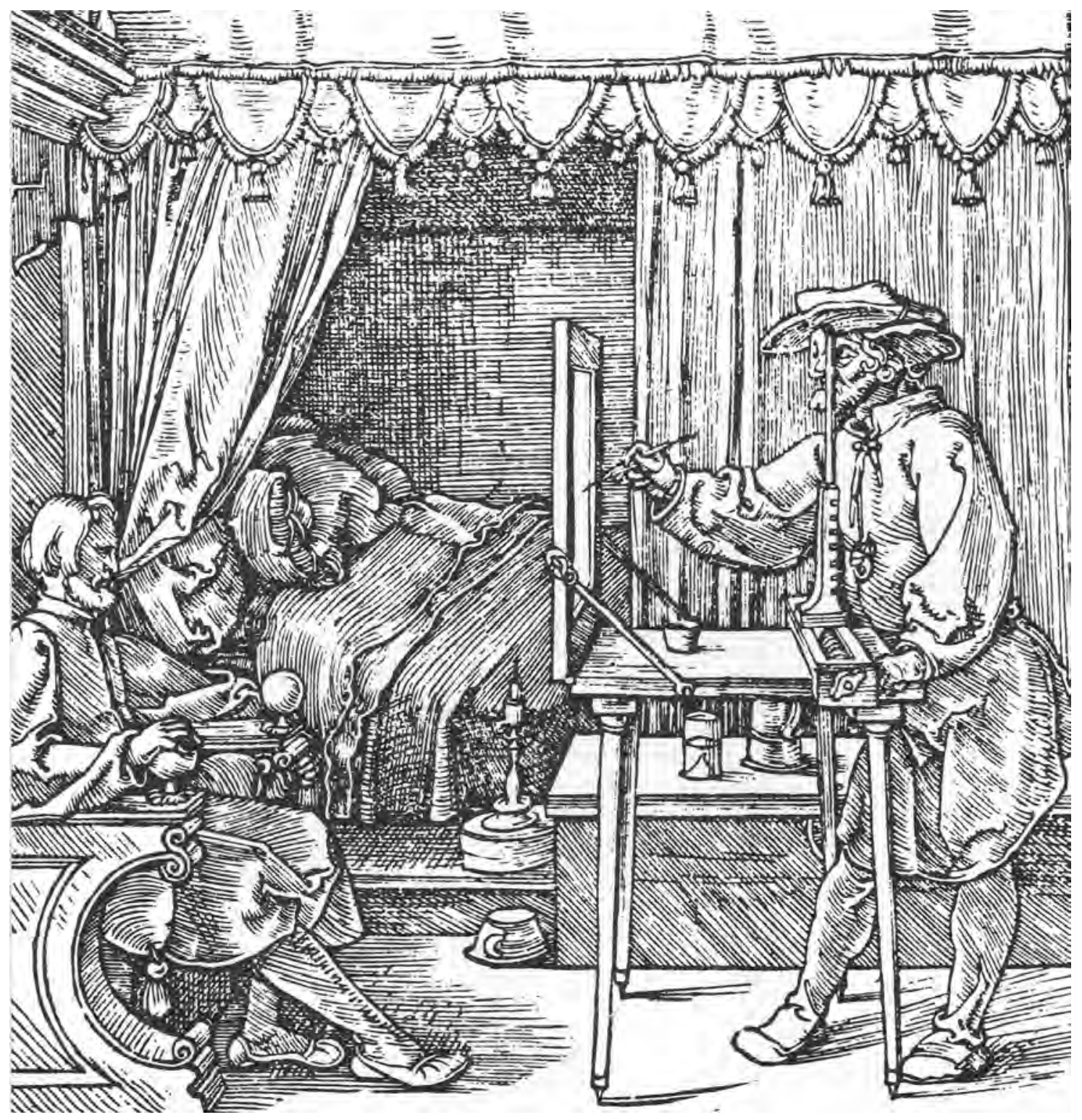

Figura 2: La comparación de Fox Keller se aplica también a un artista del Renacimiento adherido a su perspectígrafo. Albrecht Dürer: «El dibujante del hombre sentado», grabado de Instrucciones para medir (Nüremberg, 1525). Fuente: De Fiore, G. Curso de dibujo, Buenos Aires, Orbis-Hyspamerica, 1984, vol. 1, p. 158.

En coincidencia con Thuillier, Fox Keller concibe a la ciencia como construcción socialmente determinada, pero intenta, además, desentrañar el proyecto histórico-político que ha permitido la entronización de la ciencia. Cuestiona el postulado que presenta a la objetividad como un producto científico autoevidente, y examina los aspectos subjetivos que subyacen a la construcción de la objetividad científica, más específicamente, los procedimientos que se han desplegado para borrar las hueIlas de la subjetividad. La teoría feminista le provee el marco teórico de base para iniciar estas especulaciones, puesto que las marcaciones de género operan sobre las estructuras cognitivas de la modernidad identificando lo objetivo con lo masculino y lo subjetivo con lo femenino. Hemos dicho que la perspectiva clásica provee principalmente una metáfora, ya entrevista en los orígenes de la ciencia moderna, que permite resaltar determinados aspectos del conocimiento científico. En particular, esta metáfora vincula la representación perspectívica con el conocimiento descriptivo, destacando el hecho de que 
ambos se establecen por medio de procedimientos de observación y documentación fuertemente reglados. La adhesión a reglas es lo que permite legitimar los registros y conferirles autoridad, puesto que los hace depender de un ámbito autónomo, exterior al sujeto percipiente: «Corporalmente adherido a su punto de vista, como un agrimensor a su teodolito, el observador está al mismo tiempo desembarazado de sí mismo y sujeto a su técnica» (Fox Keller 1994:150) (Figura 2). Los atributos de legitimidad y objetividad de la técnica atraviesan la propia materialidad del sujeto y se trasfieren directamente a los registros por ella propulsados.

Fox Keller destaca, sin embargo, que la perspectiva clásica ofrece además una paradoja de la representación que se halla también en los albores de la ciencia moderna. El sujeto, pese a su punto de vista privilegiado, aunque justamente por causa de esto, es exterior a la representación, está ausente de lo representado y, por ende, impide una representación de la totalidad del mundo. Esta paradoja constituye uno de los problemas centrales que debe resolver la ciencia moderna: para representar el mundo en su totalidad es menester adentrar al sujeto en la representación y extirpar incluso las huellas de su exterioridad. Todavía en el siglo XVII, una representación verídica «dependía fundamentalmente del punto de vista particular del observador: de sus habilidades e instrumentos, así como de la credibilidad que su status social confería a su testimonio» (Fox Keller 1994:152). Se hacía necesario, entonces, erradicar la presencia del sujeto percipiente, del observador y autor científico, y construir un dispositivo mecánico de detección que habilite por sí mismo el realismo de las representaciones.

La historia de la construcción de este dispositivo, pensado por Fox Keller como lógica de la representación científica, se describe con los siguientes hitos: el cogito cartesiano, que escinde al sujeto percipiente del sujeto cognoscente, la definición de una técnica del informe científico, la estandarización de los instrumentos de observación y medición y, por último, la matematización de los registros científicos propiciada por el desarrollo de la estadística.

Este recorrido por la vía de una gnoseología universalizante, propiciado por las orientaciones racionalistas, conduce a lo que Popper (1972) denominó epistemología sin sujeto cognoscente, según la cual el sujeto es separable del resultado cognoscitivo y resulta, incluso, totalmente irrelevante para la tarea de la epistemología. El camino de la racionalidad moderna ha sido el de desubjetivizar el conocimiento científico hasta el punto de hacer reposar la objetividad del mismo en los procedimientos reglados que lo producen. De modo que, casi inadvertidamente, también el conocimiento se hace independiente de los procesos que lo originan.

El sujeto científico se convierte entonces en un «informante despersonalizado de los registros de un aparato mecánico de detección» (Fox Keller 1994:165). Este aparato está constituido por un método de investigación insistentemente postulado como único y universal, por instrumentos de observación y signaturas de registro progresivamente estandarizados y consensuados y, finalmente, por el acuerdo tácito de su exclusiva legitimidad. La desaparición del sujeto cognoscente desarticula la conciencia de que el conocimiento científico es una construcción humana. De este modo, desaparece la conciencia de la representación en tanto que representación y la ciencia deviene verdadera en sí y por sí misma. Por ello, cabe nuevamente poner en discusión al realismo científico: ¿qué implica en el orden ontológico la entronización de una ciencia que ignora deliberadamente la humanidad de su constitución?

\section{La perspectiva como experimento de separabilidad}

En La conquista de la abundancia, P. Feyerabend (1999) sostiene que la búsqueda de la realidad que acompaña el crecimiento de la civilización occidental tuvo un importante papel en el proceso de simplificación del mundo, pero que esta búsqueda tiene sentido sólo si lo que es real se presupone oculto, no manifiesto. Este proceso de simplificación ha seguido dos vías: la abstracción y el experimento, que han pretendido bloquear o eliminar la abundancia del ser, dejándonos con una realidad descolorida y desespiritualizada. Pero mientras que la abstracción supone una transformación en el pensamiento, donde se eliminan los rasgos particulares que distinguen a un objeto de otro; el experimento es una operación más radical, puesto que implica interferencias activas en los fenómenos, con las que se intenta bloquear los vínculos entre cada proceso y su medio. En este sentido, Brunelleschi no sólo desarrolló un sistema de representación basado en las reglas de la perspectiva central, sino que realizó un auténtico experimento.

Dicho experimento es el que reseñan algunas biografías del célebre arquitecto renacentista (Feyerabend considera la de Antonio di Tuccio Manetti, c. 1480) y consiste en la comparación entre el baptisterio de la iglesia florentina de San Giovanni con una pintura del mismo hecha según las reglas de la perspectiva central. Pero no se trata de una comparación sin más: «Brunelleschi construyó un enorme escenario, que contenía una estructura preexistente (el baptisterio), un objeto hecho por el hombre (la pintura) y arreglos especiales para la visión y proyección de ambos» (Feyerabend 1999:126) (Figura 3). 
Feyerabend hace notar, además, que aquello que se compara son los aspectos (del edificio y de la pintura) y que esta noción es ontológicamente neutral, se refiere al resultado de un procedimiento y no tiene ninguna implicación con respecto a su nivel de realidad. Sin embargo, el experimento de Brunelleschi parece otorgar existencia real a los aspectos que compara y esto es así porque el sistema de representación perspectívica modifica y articula los hábitos perceptuales existentes, haciéndolos más definidos y, en consecuencia, más excluyentes. La evidencia visual indica que esta presunta realidad se corresponde con la representación y, por lo tanto, logra disolver la sensación de que existen mediaciones entre el observador y lo observado. El hábito estereotipa determinados aspectos y les confiere status ontológico al omitir los mecanismos de proyección que les dieron origen. Pero el conocimiento, sostiene Feyerabend, es producto de desarrollos históricos idiosincrásicos y esta voluntad de separar el resultado de los procesos por los que ha sido descubierto constituye claramente una forma de realismo ingenuo.

La omisión de los mecanismos de proyección, que Feyerabend denomina presunción de separabilidad, tiene dos consecuencias. Por un lado, como las proyecciones son construcciones idiosincrásicas y culturalmente dependientes, lo que se omite es justamente la ideología que se halla en los fundamentos de la organización de la realidad. Por el otro, las proyecciones en tanto proyecciones ideológicamente determinadas, entronizan unos aspectos en detrimento de otros: «El realismo óptico que se concentra en los colores y en la geometría deja afuera la vida y el alma. 0 , para decirlo de una manera no tan ingenuamente realista: los estereotipos que se concentran en las apariencias visuales de las superficies que definen un rostro humano, no se pueden acomodar a los estereotipos de la espiritualidad» (Feyerabend 1999:137). El modelo del escenario se puede extender también a las ciencias, donde ni la naturaleza ni su representación teórica se enfrentan directamente. Por el contrario, los experimentos científicos implican una primera transformación de la naturaleza, con el objetivo de que se produzcan determinados fenómenos; una segunda transformación de la observación a través de mecanismos de registro y procesamiento de datos; y, por último, la comparación de los aspectos seleccionados en el orden de la teoría. De este modo, la realidad se convierte en parte del decorado del escenario y no en una entidad independiente. Aplicado a las ciencias, el modelo del escenario indica que la pretendida objetividad de la experimentación siempre está sujeta a determinados ajustes especiales, por lo cual la supuesta confrontación o contrastación con la realidad se debilita; ya no se trata de una realidad dada, sino fabricada de acuerdo con determinados propósitos. A su vez, esta realidad, entendida como producto, combina elementos objetivos y subjetivos. Entre los primeros, se incluyen los elementos materiales que pueden existir independientemente de la observación (aunque no de la interferencia humana); entre los segundos cuentan, fundamentalmente, todas las operaciones humanas intencionales destinadas a realizar los ajustes que se crean convenientes para el logro de ciertos propósitos.

Según Feyerabend, «viviendo en el mundo no sólo imitamos y producimos hechos, también los reproducimos al tiempo que los imitamos, y de este modo cambiamos lo que se supone que son objetos inmutables de nuestra atención. Esta compleja interacción entre lo que es y las actividades (individuales y sociales) que conducen a lo que se dice que es, hacen imposible separar la realidad y nuestras opiniones, de acuerdo con lo que exigen los realistas» (Feyerabend 1999:156).

\section{Consideraciones finales}

Las lecturas cotejadas, algunas más radicales que otras, atacan los supuestos de la tradición racionalista que preponderó en la consolidación de la racionalidad científica moderna, y que sobrevivió en gran parte de la epistemología del siglo XX. Entre esos supuestos figuran:

- una concepción de la ciencia como producto objetivo y ahistórico, con un desarrollo autónomo respecto de otras esferas de la actividad humana, y capaz de representar fielmente la naturaleza y la sociedad;

- una concepción del sujeto como desvinculado o escindido, libre y racional, productor de representaciones ob- 
jetivas que desconocen u ocultan su propia identidad y la de su contexto histórico y cultural;

- una concepción de la realidad simplificada, que sólo considera relevantes ciertos aspectos, preferentemente los que son cuantificables o geometrizables, y que en consecuencia privilegia unos criterios, en detrimento de otros, como medida para la determinación de lo real.

Las demandas de las lecturas críticas consideradas no sólo parecen exigir una ampliación de la ontología, sino también una mayor sensibilidad para captar todos los matices de la percepción, la presencia subjetiva que se ha negado, así como las relaciones, los modos de proyección y las representaciones alternativas que se han bloqueado. La revisión de los supuestos antes mencionados ya se ha abierto camino en la reflexión epistemológica contemporánea. Desde los aportes actuales, la ciencia ha de verse como una práctica social históricamente condicionada; un conocimiento público sujeto a reglas provisionales que han de ser escrutadas críticamente, y como una creación colectiva y consciente de ser un instrumento al servicio de intereses y propósitos humanos.

La imagen tradicional que ve a la ciencia (o al arte) como representación de la realidad, presupone una concepción estrecha tanto de la ciencia como de lo real. Ni la ciencia es espejo, ni lo real es algo dado que esté a la espera de ser descubierto. Antes bien, la ciencia es una creación cultural que convive con multiplicidad de otras creaciones; algunas de ellas tienen más posibilidades que otras de influir en la vida de los seres humanos. Por su parte, la realidad también es múltiple y plural, se ve afectada por nuestras actividades, lenguaje y acciones que la modifican y le otorgan nuevos significados. Pero además juzga, a su modo, las intervenciones humanas, otorgándoles vigencia y significación, o bien oponiéndoles resistencia.

Las habituales dicotomías subjetivo/objetivo; descripciones/construcciones son categorías demasiado ingenuas para orientar nuestras ideas sobre la naturaleza y las implicaciones emergentes de nuestras pretensiones de conocimiento. Seguir dogmáticamente aferrados a ellas supondría seguir jugando el juego de los tuertos.

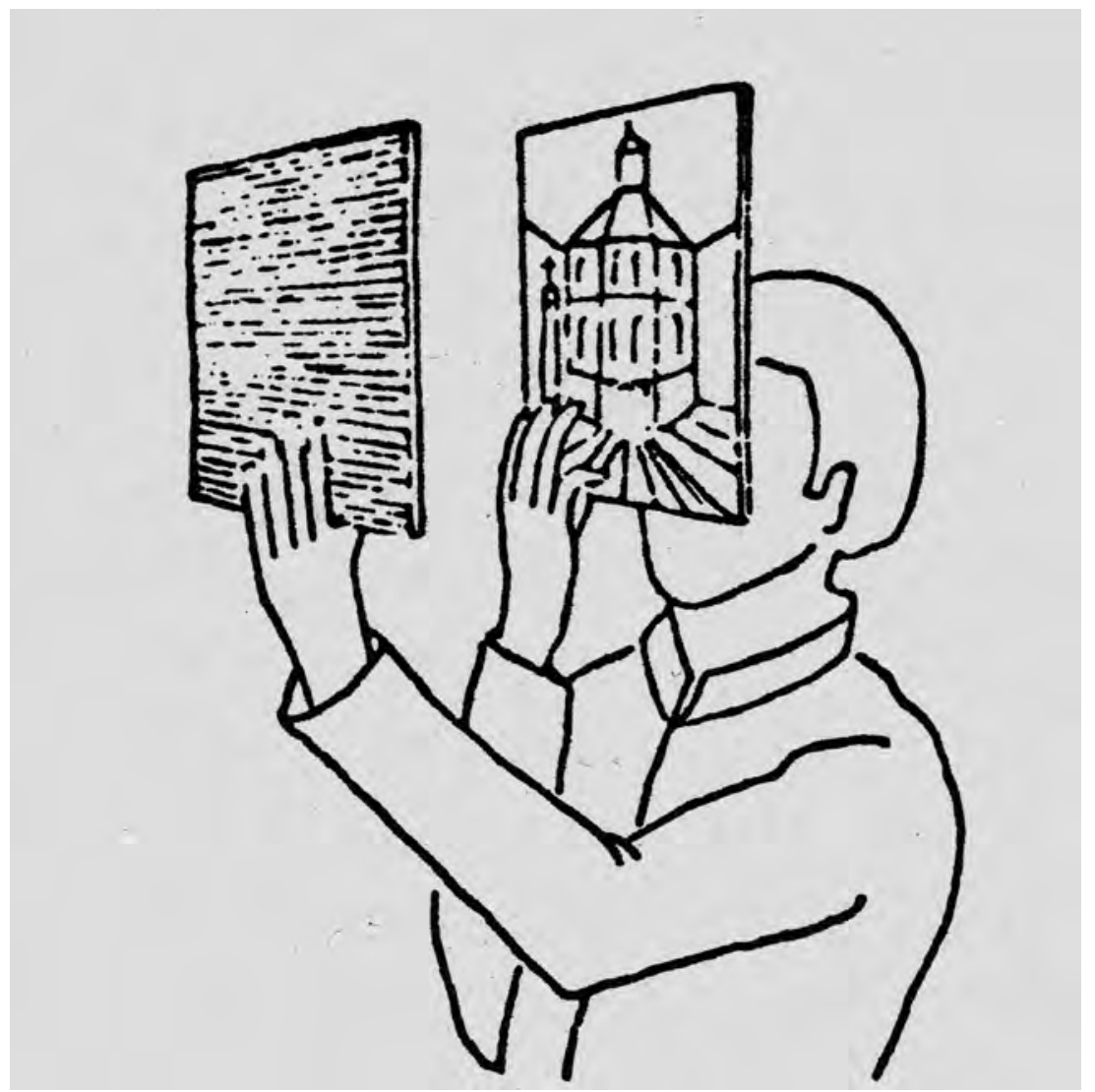

Figura 3: El experimento de Brunelleschi. Fuente: Feyerabend, P. (1999): La conquista de la abundancia. La abstracción frente a la riqueza del ser. Barcelona: Paidós, p. 120.

\section{Bibliografía}

Feyerabend, P. (1999): La conquista de la abundancia. La abstracción frente a la riqueza del ser. Barcelona: Paidós, 2001.

Fox Keller, E. (1994): «La paradoja de la subjetividad científica». En: Schnitman, D. (ed.) (1995): Nuevos paradigmas, cultura y subjetividad. Buenos Aires: Paidós, pp. 143-173. Popper, Karl (1972): Conocimiento objetivo. Madrid: Tecnos, 1982. Thuillier, Pierre (1988): De Arquímedes a Einstein. Las caras ocultas de la investigación científica. Madrid: Alianza, 1990. 